\title{
General Split Variational Inclusion Problem in Hilbert Spaces
}

\author{
Li Yang and Fu Hai Zhao \\ School of Science, South West University of Science and Technology, Mianyang, Sichuan 621010, China \\ Correspondence should be addressed to Li Yang; scmyxkdyl@163.com
}

Received 17 May 2014; Accepted 28 July 2014; Published 14 October 2014

Academic Editor: Satit Saejung

Copyright (c) 2014 L. Yang and F. H. Zhao. This is an open access article distributed under the Creative Commons Attribution License, which permits unrestricted use, distribution, and reproduction in any medium, provided the original work is properly cited.

We consider a general split variational inclusion problem (GSFVIP) and propose an algorithm for finding the solutions of GSFVIP in Hilbert space. We establish the strong convergence of the proposed algorithm to a solution of GSFVIP. Our results extend and improve the related results in the literature.

\section{Introduction}

Let $H$ be a real Hilbert space, and let $B$ be a set-valued mapping with domain $D(B):=\{x \in H: B(x) \neq \emptyset\}$. Recall that $B$ is called monotone if $\langle u-v, x-y\rangle \geq 0$ for any $u \in B x$ and $v \in B y ; B$ is maximal monotone if its graph $\{(x, y): x \in D(B), y \in B x\}$ is not properly contained in the graph of any other monotone mapping. An important problem for set-valued monotone mappings is to find $x^{*} \in H$ such that $0 \in B x^{*}$. Here, $x^{*}$ is called a zero point of $B$. A wellknown method for approximating a zero point of a maximal monotone mapping defined in a real Hilbert space is the proximal point algorithm first introduced by Martinet [1] and generated by Rockafellar [2]. This is an iterative procedure, which generates $\left\{x_{n}\right\}$ by $x_{1}=x \in H$ and

$$
x_{n+1}=J_{\beta_{n}}^{B} x_{n}, \quad n \in N,
$$

where $\left\{\beta_{n}\right\} \subset(0, \infty), B$ is a maximal monotone mapping in a real Hilbert space, and $J_{r}^{B}$ is the resolvent mapping of $B$ defined by $J_{r}^{B}=(I+r B)^{-1}$ for each $r>0$. In 1976, Rockafellar [2] proved the following in the Hilbert space setting. If the solution set $B^{-1}(0)$ is nonempty and $\liminf _{n \rightarrow \infty} \beta_{n}>0$, then the sequence $\left\{x_{n}\right\}$ in (1) converges weakly to an element of $B^{-1}(0)$. Later, many researchers have studied the convergence theorems of the proximal point algorithm in Hilbert spaces. For example, one can refer to [3-8] and references therein.

Let $H_{1}$ and $H_{2}$ be two real Hilbert spaces, $B_{1}: H_{1} \rightarrow$ $H_{1}$ and $B_{2}: H_{2} \rightarrow H_{2}$ two set-valued maximal monotone mappings, $A: H_{1} \rightarrow H_{2}$ a linear and bounded operator, and
$A^{*}$ the adjoint of $A$. Chuang [9] considers the following split variational inclusion problem:

$$
\begin{array}{r}
\text { (SFVIP) Find } x^{*} \in H_{1} \text { such that } 0 \in B_{1}\left(x^{*}\right), \\
0 \in B_{2}\left(A x^{*}\right),
\end{array}
$$

which was introduced by Moudafi [10]. In this paper, motivated by the works in Chuang [9] and related literature, we consider the following general split variational inclusion problem.

Definition 1. Let $H_{1}$ and $H_{2}$ be two real Hilbert spaces, $\left\{B_{i}: H_{1} \rightarrow H_{1}\right\}_{i \in N}$ and $\left\{K_{i}: H_{2} \rightarrow H_{2}\right\}_{i \in N}$ two families of set-valued maximal monotone mappings, $A: H_{1} \rightarrow H_{2}$ a linear and bounded operator, and $A^{*}$ the adjoint of $A$. The general split variational inclusion problem (GSFVIP) is formulated as the following problem:

$$
\begin{array}{r}
\text { (GSFVIP) Find } x^{*} \in H_{1} \text { such that } x^{*} \in \bigcap_{i=1}^{\infty} B_{i}^{-1}(0), \\
\qquad A x^{*} \in \bigcap_{i=1}^{\infty} K_{i}^{-1}(0) .
\end{array}
$$

In this paper, we propose an algorithm for finding the solutions of GSFVIP in a Hilbert space and prove that the sequence generated by the proposed method converges strongly to a solution of GSFVIP. Our results extend and improve the related results in the literature. 


\section{Preliminaries}

Throughout this paper, let $N$ be the set of positive integers. Let $H$ be a real Hilbert space with the inner product $\langle\cdot, \cdot\rangle$ and the norm $\|\cdot\|$, respectively. We also use " $\rightarrow$ " to stand for strong convergence and " $\rightarrow$ " to stand for weak convergence.

Lemma 2 (see [11]). Let $H$ be a real Hilbert space, and let $x$, $y \in H$. Then

$$
\|x+y\|^{2} \leq\|x\|^{2}+2\langle y, x+y\rangle, \quad \forall x, y \in H .
$$

Lemma 3 (see [12]). Let $H$ be a Hilbert space, and let $\left\{x_{n}\right\}$ be a sequence in $H$. Then, for any given sequence $\left\{\alpha_{n}\right\}_{n=1}^{\infty} \subset(0,1)$ with $\sum_{n=1}^{\infty} \alpha_{n}=1$ and for any positive integer $i, j$ with $i<j$,

$$
\left\|\sum_{n=1}^{\infty} \alpha_{n} x_{n}\right\|^{2} \leq \sum_{n=1}^{\infty} \alpha_{n}\left\|x_{n}\right\|^{2}-\alpha_{i} \alpha_{j}\left\|x_{i}-x_{j}\right\|^{2} .
$$

Let $D$ be a nonempty closed convex subset of a real Hilbert space $H$, and let $T: D \rightarrow H$ be a mapping. Then $T$ is said to be a nonexpansive mapping if $\|T x-T y\| \leq$ $\|x-y\|$ for every $x, y \in D$. It is easy to see that $\operatorname{Fix}(T):=$ $\{x \in D: T x=x\}$ is a closed convex subset of $D$ if $T$ is a nonexpansive mapping. Besides, $T$ is said to be a firmly nonexpansive mapping if $\|T x-T y\|^{2} \leq\langle x-y, T x-T y\rangle$ for every $x, y \in D$.

Lemma 4 (see [13]). Let $D$ be a nonempty closed convex subset of a real Hilbert space $H$. Let $T: D \rightarrow H$ be a nonexpansive mapping, and let $\left\{x_{n}\right\}$ be a sequence in D. If $x_{n} \rightarrow w$ and $\lim _{n \rightarrow \infty}\left\|x_{n}-T x_{n}\right\|=0$, then $T w=w$.

Let $D$ be a nonempty closed convex subset of $H$. For every point $x \in H$, there exists a unique nearest point in $D$, denoted by $P_{D} x$, such that

$$
\left\|x-P_{D} x\right\| \leq\|x-y\|, \quad \forall y \in D .
$$

$P_{D}$ is called the metric projection of $H$ onto $D$. It is known that $P_{D}$ is a nonexpansive mapping of $H$ onto $D$.

Lemma 5 (see [14]). Let $D$ be a nonempty closed convex subset of a Hilbert space $H$. Let $P_{D}$ be the metric projection from $H$ onto $D$. Then, for each $x \in H$ and $z \in D$, we know that $z=P_{D} x$ if and only if $\langle x-z, z-y\rangle \geq 0$ for all $y \in D$.

The following result is an important tool in this paper. For similar results, one can see [15].

Lemma 6. Let $H$ be a real Hilbert space. Let $B: H \rightarrow H$ be a set-valued maximal monotone mapping, $\beta>0$, and let $J_{\beta}^{B}$ be a resolvent mapping of $B$.

(i) For each $\beta>0, J_{\beta}^{B}$ is a single-valued and firmly nonexpansive mapping.

(ii) $D\left(J_{\beta}^{B}\right)=H$ and $\operatorname{Fix}\left(J_{\beta}^{B}\right)=\{x \in D(B): 0 \in B x\}$.

(iii) $\left\|x-J_{\beta}^{B} x\right\| \leq\left\|x-J_{\alpha}^{B} x\right\|$ for all $0<\beta \leq \alpha$ and for all $x \in H$. (iv) $\left(I-J_{\beta}^{B}\right)$ is a firmly nonexpansive mapping for each $\beta>$ 0 .

(v) Suppose that $B^{-1}(0) \neq \emptyset$. Then $\left\|x-J_{\beta}^{B} x\right\|^{2}+$ $\left\|J_{\beta}^{B} x-x^{*}\right\|^{2} \leq\left\|x-x^{*}\right\|^{2}$ for each $x \in H$, each $x^{*} \in$ $B^{-1}(0)$, and each $\beta>0$.

(vi) Suppose that $B^{-1}(0) \neq \emptyset$. Then $\left\langle x-J_{\beta}^{B} x, J_{\beta}^{B} x-w\right\rangle \geq 0$ for each $x \in H$, each $w \in B^{-1}(0)$, and each $\beta>0$.

Lemma 7 (see [9]). Let $H_{1}$ and $H_{2}$ be two real Hilbert spaces, let $A: H_{1} \rightarrow H_{2}$ be a linear operator, let $A^{*}$ be the adjoint of $A$, let $\beta>0$ be fixed, and let $\gamma \in\left(0,2 /\|A\|^{2}\right)$. Let $\mathrm{K}: \mathrm{H}_{2} \rightarrow \mathrm{H}_{2}$ be a set-valued maximal monotone mapping and let $J_{\beta}^{K}$ be a resolvent mapping of $K$. Then

$$
\begin{gathered}
\left\|\left[x-\gamma A^{*}\left(I-J_{\beta}^{K}\right) A x\right]-\left[y-\gamma A^{*}\left(I-J_{\beta}^{K}\right) A y\right]\right\|^{2} \\
\leq\|x-y\|^{2}-\left(2 \gamma-\gamma^{2}\|A\|^{2}\right) \\
\quad \times\left\|\left(I-J_{\beta}^{K}\right) A x-\left(I-J_{\beta}^{K}\right) A y\right\|^{2},
\end{gathered}
$$

for all $x, y \in H$. Furthermore, $I-\gamma A^{*}\left(I-J_{\beta}^{K}\right) A$ is a nonexpansive mapping.

The following is a very important result for various strong convergence theorems. Recently, many researchers have studied Halpern's type strong convergence theorems by using the following lemma and get many generalized results. For example, one can see $[9,16,17]$. In this paper, we also use this result to get our strong convergence theorems.

Lemma 8 (see [18]). Let $\left\{a_{n}\right\}$ be a sequence of real numbers such that there exists a subsequence $\left\{n_{i}\right\}$ of $\{n\}$ such that $a_{n_{i}}<$ $a_{n_{i}+1}$ for all $i \in N$. Then there exists a nondecreasing sequence $\{\tau(n)\} \subset N$ such that $\tau(n) \rightarrow \infty, a_{\tau(n)} \leq a_{\tau(n)+1}$, and $a_{n} \leq$ $a_{\tau(n)+1}$ are satisfied by all (sufficiently large) numbers $n \in N$. In fact, $\tau(n)=\max \left\{k \leq n: a_{k}<a_{k+1}\right\}$.

Lemma 9 (see [19]). Let $\left\{a_{n}\right\}_{n \in N}$ be a sequence of nonnegative real numbers, $\left\{\alpha_{n}\right\}$ a sequence of real numbers in $(0,1)$ with $\sum_{n=1}^{\infty} \alpha_{n}=\infty,\left\{\eta_{n}\right\}$ a sequence of nonnegative real numbers with $\sum_{n=1}^{\infty} \eta_{n}<\infty$, and $\left\{\delta_{n}\right\}$ a sequence of real numbers with $\lim \sup _{n \rightarrow \infty} \delta_{n} \leq 0$. Suppose that $a_{n+1} \leq\left(1-\alpha_{n}\right) a_{n}+\alpha_{n} \delta_{n}+\eta_{n}$ for each $n \in N$. Then $\lim _{n \rightarrow \infty} a_{n}=0$.

\section{Main Results}

In this section, we first give the following result.

Lemma 10. Let $H_{1}$ and $H_{2}$ be two real Hilbert spaces, let $A: H_{1} \rightarrow H_{2}$ be a linear and bounded operator, and let $A^{*}$ denote the adjoint of $A$. Let $\left\{B_{i}: H_{1} \rightarrow H_{1}\right\}_{i \in N}$ and $\left\{K_{i}: H_{2} \rightarrow H_{2}\right\}_{i \in N}$ be two families of set-valued maximal monotone mappings, and let $\beta_{i}>0$ and $\gamma_{i}>0$ for all $i \in N$. Given any $x^{*} \in H_{1}$, we have the following.

(i) If $x^{*}$ is a solution of GSFVIP, then $J_{\beta_{i}}^{B_{i}}\left(x^{*}-\gamma_{i} A^{*}(I-\right.$ $\left.\left.J_{\beta_{i}}^{K_{i}}\right) A x^{*}\right)=x^{*}$, for all $i \in N$. 
(ii) Suppose that $J_{\beta_{i}}^{B_{i}}\left(x^{*}-\gamma_{i} A^{*}\left(I-J_{\beta_{i}}^{K_{i}}\right) A x^{*}\right)=x^{*}$, for all $i \in N$, and that the solution set of GSFVIP is nonempty; then $x^{*}$ is a solution of GSFVIP.

Proof. (i) Suppose that $x^{*} \in H_{1}$ is a solution of GSFVIP. Then $x^{*} \in \bigcap_{i=1}^{\infty} B_{i}^{-1}(0)$ and $A x^{*} \in \bigcap_{i=1}^{\infty} K_{i}^{-1}(0)$. By Lemma 6(ii), it is easy to see that

$$
\begin{aligned}
J_{\beta_{i}}^{B_{i}} & \left(x^{*}-\gamma_{i} A^{*}\left(I-J_{\beta_{i}}^{K_{i}}\right) A x^{*}\right) \\
& =J_{\beta_{i}}^{B_{i}}\left(x^{*}-\gamma_{i} A^{*}\left(A x^{*}-J_{\beta_{i}}^{K_{i}} A x^{*}\right)\right) \\
& =J_{\beta_{i}}^{B_{i}} x^{*}=x^{*}, \quad \forall i \in N .
\end{aligned}
$$

(ii) Suppose that $w^{*}$ is a solution of GSFVIP and $x^{*}=$ $J_{\beta_{i}}^{B_{i}}\left(x^{*}-\gamma_{i} A^{*}\left(I-J_{\beta_{i}}^{K_{i}}\right) A x^{*}\right)$, for all $i \in N$. By Lemma 6(vi),

$$
\begin{array}{r}
\left\langle\left(x^{*}-\gamma_{i} A^{*}\left(I-J_{\beta_{i}}^{K_{i}}\right) A x^{*}\right)-x^{*}, x^{*}-w\right\rangle \geq 0, \\
\forall w \in B_{i}^{-1}(0), \quad \forall i \in N .
\end{array}
$$

That is,

$$
\left\langle A^{*}\left(I-J_{\beta_{i}}^{K_{i}}\right) A x^{*}, x^{*}-w\right\rangle \leq 0, \quad \forall w \in B_{i}^{-1}(0), \forall i \in N .
$$

By (10) and the fact that $A^{*}$ is the adjoint of $A$,

$$
\left\langle A x^{*}-J_{\beta_{i}}^{K_{i}} A x^{*}, A x^{*}-A w\right\rangle \leq 0, \quad \forall w \in B_{i}^{-1}(0), \forall i \in N .
$$

On the other hand, by Lemma 6(vi) again,

$$
\left\langle A x^{*}-J_{\beta_{i}}^{K_{i}} A x^{*}, v-J_{\beta_{i}}^{K_{i}} A x^{*}\right\rangle \leq 0, \quad \forall v \in K_{i}^{-1}(0), \forall i \in N \text {. }
$$

By (11) and (12),

$$
\left\langle A x^{*}-J_{\beta_{i}}^{K_{i}} A x^{*}, v-J_{\beta_{i}}^{K_{i}} A x^{*}+A x^{*}-A w\right\rangle \leq 0, \quad \forall i \in N
$$

for each $w \in B_{i}^{-1}(0)$ and each $v \in K_{i}^{-1}(0)$, for all $i \in N$. That is,

$$
\left\|A x^{*}-J_{\beta_{i}}^{K_{i}} A x^{*}\right\|^{2} \leq\left\langle A x^{*}-J_{\beta_{i}}^{K_{i}} A x^{*}, A w-v\right\rangle, \quad \forall i \in N
$$

for each $w \in B_{i}^{-1}(0)$ and each $v \in K_{i}^{-1}(0)$, for all $i \in N$. Since $w^{*}$ is a solution of GSFVIP, $w^{*} \in \bigcap_{i=1}^{\infty} B_{i}^{-1}(0)$ and $A w^{*} \epsilon$ $\bigcap_{i=1}^{\infty} K_{i}^{-1}(0)$. So, it follows from (14) that $A x^{*}=J_{\beta_{i}}^{K_{i}} A x^{*}$, for all $i \in N$. Then, $A x^{*} \in \operatorname{Fix}\left(J_{\beta_{i}}^{K_{i}}\right)=K_{i}^{-1}(0)$, for all $i \in N$. Therefore $A x^{*} \in \bigcap_{i=1}^{\infty} K_{i}^{-1}(0)$. Further,

$$
x^{*}=J_{\beta_{i}}^{B_{i}}\left(x^{*}-\gamma_{i} A^{*}\left(I-J_{\beta_{i}}^{K_{i}}\right) A x^{*}\right)=J_{\beta_{i}}^{B_{i}} x^{*}, \quad \forall i \in N .
$$

Then $x^{*} \in \operatorname{Fix}\left(J_{\beta_{i}}^{B_{i}}\right)=B_{i}^{-1}(0)$, for all $i \in N$. So, $x^{*} \in$ $\bigcap_{i=1}^{\infty} B_{i}^{-1}(0)$. Therefore, $x^{*}$ is a solution of GSFVIP.
Theorem 11. Let $H_{1}$ and $H_{2}$ be two real Hilbert spaces, let $A: H_{1} \rightarrow H_{2}$ be a linear and bounded operator, and let $A^{*}$ denote the adjoint of $A$. Let $\left\{B_{i}: H_{1} \rightarrow H_{1}\right\}_{i \in N}$ and $\left\{\mathrm{K}_{i}: \mathrm{H}_{2} \rightarrow \mathrm{H}_{2}\right\}_{i \in \mathrm{N}}$ be two families of set-valued maximal monotone mappings. Let $\left\{a_{n}\right\},\left\{b_{n}\right\},\left\{c_{n, i}\right\}$ be sequences of real numbers in $(0,1)$ with $a_{n}+b_{n}+\sum_{i=1}^{\infty} c_{n, i}=1$. Let $\left\{\beta_{n, i}\right\}$ be a sequence in $(0, \infty)$ and $\left\{\gamma_{n, i}\right\} \subset\left(0,2 /\left(\|A\|^{2}+1\right)\right)$ for each $i \in N$. Let $\Omega$ be the solution set of GSFVIP and suppose that $\Omega \neq \emptyset$. Let $f$ be a self $k$-contraction mapping of $H_{1}, k \in(0,1)$. Let $\left\{x_{n}\right\}$ be defined by

$$
\begin{aligned}
x_{n+1}= & a_{n} x_{n}+b_{n} f\left(x_{n}\right) \\
& +\sum_{i=1}^{\infty} c_{n, i} J_{\beta_{n, i}}^{B_{i}}\left(I-\gamma_{n, i} A^{*}\left(I-J_{\beta_{n, i}}^{K_{i}}\right) A\right) x_{n}, \quad n \geq 0 .
\end{aligned}
$$

If the sequences $\left\{a_{n}\right\},\left\{b_{n}\right\},\left\{c_{n, i}\right\},\left\{\beta_{n, i}\right\}$, and $\left\{\gamma_{n, i}\right\}$ satisfy the following conditions:

(i) $\lim _{n \rightarrow \infty} b_{n}=0, \sum_{n=0}^{\infty} b_{n}=\infty$,

(ii) for each $i \in N$, $\liminf _{n \rightarrow \infty} a_{n} c_{n, i}>0$, $\liminf _{n \rightarrow \infty} c_{n, i} \gamma_{n, i}>0, \liminf _{n \rightarrow \infty} \beta_{n, i}>0$, and $\limsup _{n \rightarrow \infty} \gamma_{n, i}<2 /\left(\|A\|^{2}+1\right)$,

then the sequence $\left\{x_{n}\right\}$ converges strongly to $P_{\Omega} f\left(x^{*}\right)$.

Proof. First, we show that $\left\{x_{n}\right\}$ is bounded. In fact, let $z \in \Omega$; it follows from Lemmas 6(i) and 7 that $J_{\beta_{n, i}}^{B_{i}}\left(I-\gamma_{n, i} A^{*}\left(I-J_{\beta_{n, i}}^{K_{i}}\right) A\right)$, for all $i \in N$, are nonexpansive, and by Lemma 10 we have

$$
\begin{aligned}
\left\|x_{n+1}-z\right\| & \| a_{n} x_{n}+b_{n} f\left(x_{n}\right) \\
& +\sum_{i=1}^{\infty} c_{n, i} J_{\beta_{n, i}}^{B_{i}}\left(I-\gamma_{n, i} A^{*}\left(I-J_{\beta_{n, i}}^{K_{i}}\right) A\right) x_{n}-z \| \\
\leq & a_{n}\left\|x_{n}-z\right\|+b_{n}\left\|f\left(x_{n}\right)-z\right\| \\
& +\sum_{i=1}^{\infty} c_{n, i}\left\|J_{\beta_{n, i}}^{B_{i}}\left(I-\gamma_{n, i} A^{*}\left(I-J_{\beta_{n, i}}^{K_{i}}\right) A\right) x_{n}-z\right\| \\
\leq & a_{n}\left\|x_{n}-z\right\|+b_{n}\left\|f\left(x_{n}\right)-z\right\|+\sum_{i=1}^{\infty} c_{n, i}\left\|x_{n}-z\right\|
\end{aligned}
$$




$$
\begin{aligned}
\leq & \left(1-b_{n}\right)\left\|x_{n}-z\right\|+b_{n}\left\|f\left(x_{n}\right)-z\right\| \\
\leq & \left(1-b_{n}\right)\left\|x_{n}-z\right\| \\
& +b_{n}\left\|f\left(x_{n}\right)-f(z)\right\|+b_{n}\|f(z)-z\| \\
\leq & \left(1-b_{n}\right)\left\|x_{n}-z\right\|+b_{n} k\left\|x_{n}-z\right\|+b_{n}\|f(z)-z\| \\
\leq & \left(1-(1-k) b_{n}\right)\left\|x_{n}-z\right\| \\
& +(1-k) b_{n} \frac{1}{1-k}\|f(z)-z\| \\
\leq & \max \left\{\left\|x_{n}-z\right\|, \frac{1}{1-k}\|f(z)-z\|\right\} \\
\leq & \cdots \leq \max \left\{\left\|x_{0}-z\right\|, \frac{1}{1-k}\|f(z)-z\|\right\},
\end{aligned}
$$

which implies that $\left\{x_{n}\right\}$ is bounded, and we also obtain that $\left\{f\left(x_{n}\right)\right\}$ is bounded.

Next, we show that there exists a unique $x^{*} \in \Omega$ such that $x^{*}=P_{\Omega} f\left(x^{*}\right)$.

Since, for all $i \in N$, $\liminf _{n \rightarrow \infty} \beta_{n, i}>0$, we may assume that $\beta_{n, i}>\beta_{i}>0$ for each $n \in N$. Since, for all $i \in N,\left\{\gamma_{n, i}\right\}$ is bounded, there exists a converge subsequence. Without loss of generality, we can assume that $\gamma_{n, i} \rightarrow \gamma_{i} \in\left(0,2 /\left(\|A\|^{2}+1\right)\right)$ for each $i \in N$.

It follows from Lemma 10 that $x^{*} \in \Omega$ solves the GSFVIP if and only if $x^{*}$ solves the fixed point equation

$$
x^{*}=J_{\beta_{i}}^{B_{i}}\left(I-\gamma_{i} A^{*}\left(I-J_{\beta_{i}}^{K_{i}}\right) A\right) x^{*}, \quad i \in N
$$

that is, the solution sets of fixed point equation (18) and GSFVIP are the same. By Lemmas 6(i) and 7, the operators $J_{\beta_{i}}^{B_{i}}\left(I-\gamma_{i} A^{*}\left(I-J_{\beta_{i}}^{K_{i}}\right) A\right)$, for all $i \in N$, are nonexpansive. Since the fixed point set of nonexpansive operators is closed and convex, the projection onto the solution set $\Omega$ is well defined whenever $\Omega \neq \emptyset$. We observe that $P_{\Omega} f$ is a contraction of $H_{1}$ into itself. Indeed, since $P_{\Omega}$ is nonexpansive and $f$ is a self $k$-contraction mapping $H_{1}$,

$$
\left\|P_{\Omega}(f)(x)-P_{\Omega}(f)(y)\right\| \leq\|f(x)-f(y)\| \leq k\|x-y\| .
$$

Hence, there exists a unique element $x^{*} \in \Omega$ such that $x^{*}=$ $P_{\Omega} f\left(x^{*}\right)$.

In order to prove that $x_{n} \rightarrow x^{*}$ as $n \rightarrow \infty$, we consider two possible cases.

Case 1. There exists a natural number $n_{0}$ such that $\| x_{n+1}-$ $x^{*}\|\leq\| x_{n}-x^{*} \|$ for each $n \geq n_{0}$. Since $\left\{\left\|x_{n}-x^{*}\right\|\right\}$ is bounded, we have $\left\{\left\|x_{n}-x^{*}\right\|\right\}$ is convergent.

Next, we show that, for each $i \in N$,

$$
\lim _{n \rightarrow \infty}\left\|J_{\beta_{i}}^{B_{i}}\left(I-\gamma_{i} A^{*}\left(I-J_{\beta_{i}}^{K_{i}}\right) A\right) x_{n}-x_{n}\right\|=0
$$

By Lemmas 6(i) and 7, for every $z \in \Omega$ and $i \in N$, we have

$$
\begin{aligned}
\left\|J_{\beta_{n, i}}^{B_{i}}\left(I-\gamma_{n, i} A^{*}\left(I-J_{\beta_{n, i}}^{K_{i}}\right) A\right) x_{n}-z\right\| \\
\leq \|\left(x_{n}-\gamma_{n, i} A^{*}\left(I-J_{\beta_{n, i}}^{K_{i}}\right) A x_{n}\right) \\
\quad-\left(z-\gamma_{n, i} A^{*}\left(I-J_{\beta_{n, i}}^{K_{i}}\right) A z\right) \| \\
\leq\left\|x_{n}-z\right\|^{2}-\left(2 \gamma_{n, i}-\gamma_{n, i}^{2}\|A\|^{2}\right) \\
\quad \times\left\|\left(I-J_{\beta_{n, i}}^{K_{i}}\right) A x_{n}-\left(I-J_{\beta_{n, i}}^{K_{i}}\right) A z\right\|^{2} \\
=\left\|x_{n}-z\right\|^{2}-\left(2 \gamma_{n, i}-\gamma_{n, i}^{2}\|A\|^{2}\right) \\
\times\left\|A x_{n}-J_{\beta_{n, i}}^{K_{i}} A x_{n}\right\|^{2} .
\end{aligned}
$$

By using Lemma 3 and (21), for every $z \in \Omega$ and $i \in N$, we have

$$
\begin{aligned}
\left\|x_{n+1}-z\right\|^{2} & \| a_{n} x_{n}+b_{n} f\left(x_{n}\right) \\
& +\sum_{j=1}^{\infty} c_{n, j} J_{\beta_{n, j}}^{B_{j}}\left(I-\gamma_{n, j} A^{*}\left(I-J_{\beta_{n, j}}^{K_{j}}\right) A\right) x_{n}-z \|^{2} \\
\leq & a_{n}\left\|x_{n}-z\right\|^{2}+b_{n}\left\|f\left(x_{n}\right)-z\right\|^{2} \\
& +\sum_{j=1}^{\infty} c_{n, j}\left\|J_{\beta_{n, j}}^{B_{j}}\left(I-\gamma_{n, j} A^{*}\left(I-J_{\beta_{n, j}}^{K_{j}}\right) A\right) x_{n}-z\right\|^{2} \\
& -a_{n} c_{n, i}\left\|J_{\beta_{n, i}}^{B_{i}}\left(I-\gamma_{n, i} A^{*}\left(I-J_{\beta_{n, i}}^{K_{i}}\right) A\right) x_{n}-x_{n}\right\|^{2} \\
\leq & a_{n}\left\|x_{n}-z\right\|^{2}+b_{n}\left\|f\left(x_{n}\right)-z\right\|^{2} \\
& +\sum_{n, i}^{\infty} c_{n, j}\left(\left\|x_{n}-z\right\|^{2}\right. \\
& \quad-a_{n} c_{n, i}\left\|J_{\beta_{n, i}}^{B_{i}}\left(I-\gamma_{n, i} A^{*}\left(I-J_{\beta_{n, i}}^{K_{i}}\right) A\right) x_{n}-x_{n}\right\|_{\beta_{n, i}}^{B_{i}}\left(I-\gamma_{n, i} A^{*}\left(I-J_{\beta_{n, i}}^{K_{i}}\right) A\right) x_{n}-x_{n} \|^{2} . \\
& \left.\quad-\left(2 x_{n, j}-\gamma_{n, j}^{2}\|A\|^{2}\right)\left\|A x_{n}-b_{n}\right\| f\left(x_{n}\right)-z\left\|_{\beta_{n, j}}^{K_{j}} A x_{n}\right\|^{2}\right)
\end{aligned}
$$


Hence, for each $i \in N$, we have

$$
\begin{aligned}
& a_{n} c_{n, i}\left\|J_{\beta_{n, i}}^{B_{i}}\left(I-\gamma_{n, i} A^{*}\left(I-J_{\beta_{n, i}}^{K_{i}}\right) A\right) x_{n}-x_{n}\right\|^{2} \\
& \leq\left\|x_{n}-z\right\|^{2}-\left\|x_{n+1}-z\right\|^{2}+b_{n}\left\|f\left(x_{n}\right)-z\right\|^{2}, \\
& c_{n, i}\left(2 \gamma_{n, i}-\gamma_{n, i}^{2}\|A\|^{2}\right)\left\|A x_{n}-J_{\beta_{n, i}}^{K_{i}} A x_{n}\right\|^{2} \\
& \leq\left\|x_{n}-z\right\|^{2}-\left\|x_{n+1}-z\right\|^{2}+b_{n}\left\|f\left(x_{n}\right)-z\right\|^{2} .
\end{aligned}
$$

Since $\lim _{n \rightarrow \infty} b_{n}=0$ and $f\left(x_{n}\right)$ is bounded, from (23) we get that

$$
\lim _{n \rightarrow \infty} a_{n} c_{n, i}\left\|J_{\beta_{n, i}}^{B_{i}}\left(I-\gamma_{n, i} A^{*}\left(I-J_{\beta_{n, i}}^{K_{i}}\right) A\right) x_{n}-x_{n}\right\|^{2}=0,
$$$$
\forall i \in N \text {, }
$$

$$
\lim _{n \rightarrow \infty} c_{n, i}\left(2 \gamma_{n, i}-\gamma_{n, i}^{2}\|A\|^{2}\right)\left\|A x_{n}-J_{\beta_{n, i}}^{K_{i}} A x_{n}\right\|^{2}=0, \quad \forall i \in N .
$$

By assuming that, for all $i \in N$, $\liminf _{n \rightarrow \infty} a_{n} c_{n, i}>0$, it follows from (24) that

$$
\lim _{n \rightarrow \infty}\left\|J_{\beta_{n, i}}^{B_{i}}\left(I-\gamma_{n, i} A^{*}\left(I-J_{\beta_{n, i}}^{K_{i}}\right) A\right) x_{n}-x_{n}\right\|=0, \quad \forall i \in N .
$$

Further, for all $i \in N$, we have

$$
\begin{aligned}
& \left\|J_{\beta_{n, i}}^{B_{i}}\left(I-\gamma_{i} A^{*}\left(I-J_{\beta_{n, i}}^{K_{i}}\right) A\right) x_{n}-x_{n}\right\| \\
& \leq \| J_{\beta_{n, i}}^{B_{i}}\left(I-\gamma_{i} A^{*}\left(I-J_{\beta_{n, i}}^{K_{i}}\right) A\right) x_{n} \\
& \quad-J_{\beta_{n, i}}^{B_{i}}\left(I-\gamma_{n, i} A^{*}\left(I-J_{\beta_{n, i}}^{K_{i}}\right) A\right) x_{n} \| \\
& +\left\|J_{\beta_{n, i}}^{B_{i}}\left(I-\gamma_{n, i} A^{*}\left(I-J_{\beta_{n, i}}^{K_{i}}\right) A\right) x_{n}-x_{n}\right\| \\
& \leq \|\left(I-\gamma_{i} A^{*}\left(I-J_{\beta_{n, i}}^{K_{i}}\right) A\right) x_{n} \\
& \quad-\left(I-\gamma_{n, i} A^{*}\left(I-J_{\beta_{n, i}}^{K_{i}}\right) A\right) x_{n} \| \\
& \quad+\left\|J_{\beta_{n, i}}^{B_{i}}\left(I-\gamma_{n, i} A^{*}\left(I-J_{\beta_{n, i}}^{K_{i}}\right) A\right) x_{n}-x_{n}\right\| \\
& \leq\left|\gamma_{i}-\gamma_{n, i}\right|\left\|A^{*}\left(I-J_{\beta_{n, i}}^{K_{i}}\right) A x_{n}\right\| \\
& \quad+\left\|J_{\beta_{n, i}}^{B_{i}}\left(I-\gamma_{n, i} A^{*}\left(I-J_{\beta_{n, i}}^{K_{i}}\right) A\right) x_{n}-x_{n}\right\| \longrightarrow 0
\end{aligned}
$$

Clearly, for all $i \in N, c_{n, i}\left(2 \gamma_{n, i}-\gamma_{n, i}^{2}\|A\|^{2}\right) \geq c_{n, i} \gamma_{n, i} /\left(\|A\|^{2}+1\right)$. Since, for all $i \in N$, $\liminf _{n \rightarrow \infty} c_{n, i} \gamma_{n, i}>0$, it follows from (25) that

$$
\lim _{n \rightarrow \infty}\left\|A x_{n}-J_{\beta_{n, i}}^{K_{i}} A x_{n}\right\|=0, \quad \forall i \in N
$$

and it follows from Lemma 6(iii) that

$$
\lim _{n \rightarrow \infty}\left\|A x_{n}-J_{\beta_{i}}^{K_{i}} A x_{n}\right\|=0, \quad \forall i \in N .
$$

Besides, by Lemma 6(i) and (28), for all $i \in N$, we have

$$
\begin{aligned}
& \left\|J_{\beta_{n, i}}^{B_{i}}\left(I-\gamma_{i} A^{*}\left(I-J_{\beta_{n, i}}^{K_{i}}\right) A\right) x_{n}-J_{\beta_{n, i}}^{B_{i}} x_{n}\right\| \\
& \quad \leq \gamma_{i}\|A\|\left\|A x_{n}-J_{\beta_{n, i}}^{K_{i}} A x_{n}\right\| \longrightarrow 0 \quad(n \longrightarrow \infty) .
\end{aligned}
$$

By (27) and (30), for all $i \in N$, we obtain

$$
\begin{aligned}
& \left\|x_{n}-J_{\beta_{n, i}}^{B_{i}} x_{n}\right\| \\
& \leq\left\|x_{n}-J_{\beta_{n, i}}^{B_{i}}\left(I-\gamma_{i} A^{*}\left(I-J_{\beta_{n, i}}^{K_{i}}\right) A\right) x_{n}\right\| \\
& \quad+\left\|J_{\beta_{n, i}}^{B_{i}}\left(I-\gamma_{i} A^{*}\left(I-J_{\beta_{n, i}}^{K_{i}}\right) A\right) x_{n}-J_{\beta_{n, i}}^{B_{i}} x_{n}\right\| \longrightarrow 0 \\
& (n \longrightarrow \infty) .
\end{aligned}
$$

It follows from Lemma 6(iii) that

$$
\lim _{n \rightarrow \infty}\left\|x_{n}-J_{\beta_{i}}^{B_{i}} x_{n}\right\|=0, \quad \forall i \in N .
$$

By Lemma 6(i) and (29), for all $i \in N$, we have

$$
\begin{aligned}
& \left\|J_{\beta_{i}}^{B_{i}}\left(I-\gamma_{i} A^{*}\left(I-J_{\beta_{i}}^{K_{i}}\right) A\right) x_{n}-J_{\beta_{i}}^{B_{i}} x_{n}\right\| \\
& \quad \leq \gamma_{i}\|A\|\left\|A x_{n}-J_{\beta_{i}}^{K_{i}} A x_{n}\right\| \longrightarrow 0 \quad(n \longrightarrow \infty) .
\end{aligned}
$$

By (32) and (33), for all $i \in N$, we obtain

$$
\lim _{n \rightarrow \infty}\left\|J_{\beta_{i}}^{B_{i}}\left(I-\gamma_{i} A^{*}\left(I-J_{\beta_{i}}^{K_{i}}\right) A\right) x_{n}-x_{n}\right\|=0 .
$$

Now, we show that

$$
\limsup _{n \rightarrow \infty}\left\langle f\left(x^{*}\right)-x^{*}, x_{n}-x^{*}\right\rangle \leq 0 .
$$

To show this inequality, we choose a subsequence $\left\{x_{n_{k}}\right\}$ of $\left\{x_{n}\right\}$ such that

$$
\begin{aligned}
& \lim _{k \rightarrow \infty}\left\langle f\left(x^{*}\right)-x^{*}, x_{n_{k}}-x^{*}\right\rangle \\
& \quad=\limsup _{n \rightarrow \infty}\left\langle f\left(x^{*}\right)-x^{*}, x_{n}-x^{*}\right\rangle .
\end{aligned}
$$

Since $\left\{x_{n_{k}}\right\}$ is bounded, there exists a subsequence $\left\{x_{n_{k_{j}}}\right\}$ of $\left\{x_{n_{k}}\right\}$ which converges weakly to $w$. Without loss of generality, we can assume that $x_{n_{k}} \rightarrow w$. Notice that, for each $i \in N$, $J_{\beta_{i}}^{B_{i}}\left(I-\gamma_{i} A^{*}\left(I-J_{\beta_{i}}^{K_{i}}\right) A\right)$ is nonexpansive. Thus, from Lemma 4 and (34), we have $w \in \Omega$. Therefore, it follows from Lemma 5 that

$$
\begin{aligned}
& \limsup _{n \rightarrow \infty}\left\langle f\left(x^{*}\right)-x^{*}, x_{n}-x^{*}\right\rangle \\
& \quad=\lim _{k \rightarrow \infty}\left\langle f\left(x^{*}\right)-x^{*}, x_{n_{k}}-x^{*}\right\rangle \\
& =\left\langle f\left(x^{*}\right)-x^{*}, w-x^{*}\right\rangle \leq 0 .
\end{aligned}
$$


Finally, we show that $x_{n} \rightarrow x^{*}$. Applying Lemma 2, we have that

$$
\begin{aligned}
& \left\|x_{n+1}-x^{*}\right\|^{2} \\
& =\| a_{n} x_{n}+b_{n} f\left(x_{n}\right) \\
& +\sum_{i=1}^{\infty} c_{n, i} J_{\beta_{n, i}}^{B_{i}}\left(I-\gamma_{n, i} A^{*}\left(I-J_{\beta_{n, i}}^{K_{i}}\right) A\right) x_{n}-x^{*} \|^{2} \\
& \leq \| a_{n}\left(x_{n}-x^{*}\right) \\
& +\sum_{i=1}^{\infty} c_{n, i}\left(J_{\beta_{n, i}}^{B_{i}}\left(I-\gamma_{n, i} A^{*}\left(I-J_{\beta_{n, i}}^{K_{i}}\right) A\right) x_{n}-x^{*}\right) \\
& +b_{n}\left(f\left(x_{n}\right)-x^{*}\right) \|^{2} \\
& \leq a_{n}\left(x_{n}-x^{*}\right) \\
& +\sum_{i=1}^{\infty} c_{n, i}\left(J_{\beta_{n, i}}^{B_{i}}\left(I-\gamma_{n, i} A^{*}\left(I-J_{\beta_{n, i}}^{K_{i}}\right) A\right) x_{n}-x^{*}\right) \|^{2} \\
& +2 b_{n}\left\langle f\left(x_{n}\right)-x^{*}, x_{n+1}-x^{*}\right\rangle \\
& \leq\left(a_{n}\left\|x_{n}-x^{*}\right\|+\sum_{i=1}^{\infty} c_{n, i}\left\|x_{n}-x^{*}\right\|\right)^{2} \\
& +2 b_{n}\left\langle f\left(x_{n}\right)-x^{*}, x_{n+1}-x^{*}\right\rangle \\
& \leq\left(1-b_{n}\right)^{2}\left\|x_{n}-x^{*}\right\|^{2}+2 b_{n}\left\langle f\left(x_{n}\right)-f\left(x^{*}\right), x_{n+1}-x^{*}\right\rangle \\
& +2 b_{n}\left\langle f\left(x^{*}\right)-x^{*}, x_{n+1}-x^{*}\right\rangle \\
& \leq\left(1-b_{n}\right)^{2}\left\|x_{n}-x^{*}\right\|^{2}+2 b_{n} k\left\|x_{n}-x^{*}\right\|\left\|x_{n+1}-x^{*}\right\| \\
& +2 b_{n}\left\langle f\left(x^{*}\right)-x^{*}, x_{n+1}-x^{*}\right\rangle \\
& \leq\left(1-b_{n}\right)^{2}\left\|x_{n}-x^{*}\right\|^{2}+b_{n} k\left(\left\|x_{n}-x^{*}\right\|^{2}+\left\|x_{n+1}-x^{*}\right\|^{2}\right) \\
& +2 b_{n}\left\langle f\left(x^{*}\right)-x^{*}, x_{n+1}-x^{*}\right\rangle \text {. }
\end{aligned}
$$

This implies that

$$
\begin{aligned}
\left\|x_{n+1}-x^{*}\right\|^{2} & \\
\leq & \frac{\left(1-b_{n}\right)^{2}+b_{n} k}{1-b_{n} k}\left\|x_{n}-x^{*}\right\|^{2} \\
& +\frac{2 b_{n}}{1-b_{n} k}\left\langle f\left(x^{*}\right)-x^{*}, x_{n+1}-x^{*}\right\rangle
\end{aligned}
$$

$$
\begin{aligned}
&= \frac{1-2 b_{n}+b_{n} k}{1-b_{n} k}\left\|x_{n}-x^{*}\right\|^{2}+\frac{b_{n}^{2}}{1-b_{n} k}\left\|x_{n}-x^{*}\right\|^{2} \\
&+\frac{2 b_{n}}{1-b_{n} k}\left\langle f\left(x^{*}\right)-x^{*}, x_{n+1}-x^{*}\right\rangle \\
&=\left(1-\frac{2(1-k) b_{n}}{1-b_{n} k}\right)\left\|x_{n}-x^{*}\right\|^{2} \\
&+\frac{2(1-k) b_{n}}{1-b_{n} k}\left\{\frac{b_{n} M}{2(1-k)}\right. \\
&\left.\quad+\frac{1}{1-k}\left\langle f\left(x^{*}\right)-x^{*}, x_{n+1}-x^{*}\right\rangle\right\} \\
&=\left(1-\alpha_{n}\right)\left\|x_{n}-x^{*}\right\|^{2}+\alpha_{n} \delta_{n},
\end{aligned}
$$

where $\delta_{n}=b_{n} M / 2(1-k)+(1 /(1-k))\left\langle f\left(x^{*}\right)-x^{*}, x_{n+1}-x^{*}\right\rangle$, $M=\sup \left\{\left\|x_{n}-x^{*}\right\|^{2}: n \geq 0\right\}$, and $\alpha_{n}=2(1-k) b_{n} /(1-$ $\left.b_{n} k\right)$. It is easy to see that $\lim _{n \rightarrow \infty} \alpha_{n}=0, \sum_{n=1}^{\infty} \alpha_{n}=\infty$, and $\lim \sup _{n \rightarrow \infty} \delta_{n} \leq 0$. Hence, by Lemma 9, the sequence $\left\{x_{n}\right\}$ converges strongly to $x^{*}=P_{\Omega} f\left(x^{*}\right)$.

Case 2. Assume that $\left\{\left\|x_{n}-x^{*}\right\|\right\}$ is not a monotone sequence. Then, we can define an integer sequence $\{\tau(n)\}$ for all $n \geq n_{0}$ (for some $n_{0}$ large enough) by

$$
\tau(n)=\max \left\{k \in N ; k \leq n:\left\|x_{k}-x^{*}\right\|<\left\|x_{k+1}-x^{*}\right\|\right\} .
$$

Clearly, $\{\tau(n)\}$ is a nondecreasing sequence such that $\tau(n) \rightarrow$ $\infty$ as $n \rightarrow \infty$ for all $n \geq n_{0}$ :

$$
\left\|x_{\tau(n)}-x^{*}\right\|<\left\|x_{\tau(n)+1}-x^{*}\right\| .
$$

Following a similar argument as the proof of Case 1, we have

$$
\limsup _{n \rightarrow \infty}\left\langle f\left(x^{*}\right)-x^{*}, x_{\tau(n)}-x^{*}\right\rangle \leq 0
$$

And by similar argument, we have

$$
\left\|x_{\tau(n)+1}-x^{*}\right\|^{2}=\left(1-\alpha_{\tau(n)}\right)\left\|x_{\tau(n)}-x^{*}\right\|^{2}+\alpha_{\tau(n)} \delta_{\tau(n)},
$$

where $\lim _{n \rightarrow \infty} \alpha_{\tau(n)}=0, \sum_{n=1}^{\infty} \alpha_{\tau(n)}=\infty$, and $\limsup \operatorname{sum}_{n \rightarrow \infty} \delta_{\tau(n)} \leq 0$. Hence, by Lemma 9, we obtain $\lim _{n \rightarrow \infty}\left\|x_{\tau(n)}-x^{*}\right\|=0$ and $\lim _{n \rightarrow \infty}\left\|x_{\tau(n)+1}-x^{*}\right\|=0$. Now, from Lemma 8, we have

$$
0 \leq\left\|x_{n}-x^{*}\right\| \leq\left\|x_{\tau(n)+1}-x^{*}\right\| .
$$

Therefore, the sequence $\left\{x_{n}\right\}$ converges strongly to $x^{*}=$ $P_{\Omega} f\left(x^{*}\right)$. This completes the proof.

Corollary 12. Let $H_{1}$ and $H_{2}$ be two real Hilbert spaces, let $A: H_{1} \rightarrow H_{2}$ be a linear and bounded operator, and let $A^{*}$ denote the adjoint of $A$. Let $\left\{B_{i}: H_{1} \rightarrow H_{1}\right\}_{i \in N}$ and $\left\{K_{i}: H_{2} \rightarrow H_{2}\right\}_{i \in N}$ be two families of set-valued maximal monotone mappings for all $i \in N$. Let $\left\{a_{n}\right\},\left\{c_{n, i}\right\}$ be sequences of real numbers in $(0,1)$ with $a_{n}+\sum_{i=1}^{\infty} c_{n, i} \subset(0,1)$. Let $\left\{\beta_{n, i}\right\}$ 
be a sequence in $(0, \infty)$ and $\left\{\gamma_{n, i}\right\} \subset\left(0,2 /\left(\|A\|^{2}+1\right)\right)$ for each $i \in N$. Let $\Omega$ be the solution set of GSFVIP and suppose that $\Omega \neq \emptyset$. Let $\left\{x_{n}\right\}$ be defined by

$$
x_{n+1}=a_{n} x_{n}+\sum_{i=1}^{\infty} c_{n, i} J_{\beta_{n, i}}^{B_{i}}\left(I-\gamma_{n, i} A^{*}\left(I-J_{\beta_{n, i}}^{K_{i}}\right) A\right) x_{n},
$$

$n \geq 0$.

If the sequences $\left\{a_{n}\right\},\left\{c_{n, i}\right\},\left\{\beta_{n, i}\right\}$, and $\left\{\gamma_{n, i}\right\}$ satisfy the following conditions:

(i) $\lim _{n \rightarrow \infty}\left(a_{n}+\sum_{i=1}^{\infty} c_{n, i}\right)=1, \sum_{n=0}^{\infty}\left(1-a_{n}-\sum_{i=1}^{\infty} c_{n, i}\right)=$ $\infty$,

(ii) for each $i \in N$, $\liminf _{n \rightarrow \infty} a_{n} c_{n, i}>0$, $\liminf _{n \rightarrow \infty} c_{n, i} \gamma_{n, i}>0, \liminf _{n \rightarrow \infty} \beta_{n, i}>0$, and $\limsup _{n \rightarrow \infty} \gamma_{n, i}<2 /\left(\|A\|^{2}+1\right)$,

then the sequence $\left\{x_{n}\right\}$ converges strongly to a point $x^{*}$ which is the minimum norm solution of GSFVIP.

Proof. Let $f=0$ in Theorem 11. We have proved that the sequence $\left\{x_{n}\right\}$ converges strongly to $x^{*}=P_{\Omega} f\left(x^{*}\right)$. Then, for all $z \in \Omega$, we have

$$
\begin{aligned}
& \left\langle f\left(x^{*}\right)-x^{*}, z-x^{*}\right\rangle \\
& \quad=\left\langle f\left(x^{*}\right)-P_{\Omega} f\left(x^{*}\right), z-P_{\Omega} f\left(x^{*}\right)\right\rangle \leq 0 .
\end{aligned}
$$

Since $f=0$, then $\left\langle-x^{*}, z-x^{*}\right\rangle \leq 0$, for all $z \in \Omega$. Hence, we obtain

$$
\left\|x^{*}\right\|^{2} \leq\left|\left\langle x^{*}, z\right\rangle\right| \leq\left\|x^{*}\right\|\|z\|
$$

that is, $\left\|x^{*}\right\| \leq\|z\|$. Thus, $x^{*}$ is the minimum norm solution of GSFVIP. This completes the proof.

In Theorem 11, if we set $f(x)=u$, then we get the following result.

Corollary 13. Let $H_{1}$ and $H_{2}$ be two real Hilbert spaces, let $A: H_{1} \rightarrow H_{2}$ be a linear and bounded operator, and let $A^{*}$ denote the adjoint of $A$. Let $\left\{B_{i}: H_{1} \rightarrow H_{1}\right\}_{i \in N}$ and $\left\{K_{i}: H_{2} \rightarrow H_{2}\right\}_{i \in N}$ be two families of set-valued maximal monotone mappings for all $i \in N$. Let $\left\{a_{n}\right\},\left\{b_{n}\right\},\left\{c_{n, i}\right\}$ be sequences of real numbers in $(0,1)$ with $a_{n}+b_{n}+\sum_{i=1}^{\infty} c_{n, i}=1$. Let $\left\{\beta_{n, i}\right\}$ be a sequence in $(0, \infty)$ and $\left\{\gamma_{n, i}\right\} \subset\left(0,2 /\left(\|A\|^{2}+1\right)\right)$ for each $i \in N$. Let $u \in H_{1}$ be fixed. Let $\Omega$ be the solution set of GSFVIP and suppose that $\Omega \neq \emptyset$. Let $\left\{x_{n}\right\}$ be defined by

$$
\begin{aligned}
x_{n+1}= & a_{n} x_{n}+b_{n} u \\
& +\sum_{i=1}^{\infty} c_{n, i} J_{\beta_{n, i}}^{B_{i}}\left(I-\gamma_{n, i} A^{*}\left(I-J_{\beta_{n, i}}^{K_{i}}\right) A\right) x_{n}, \quad n \geq 0 .
\end{aligned}
$$

If the sequences $\left\{a_{n}\right\},\left\{b_{n}\right\},\left\{c_{n, i}\right\},\left\{\beta_{n, i}\right\}$, and $\left\{\gamma_{n, i}\right\}$ satisfy the following conditions:

(i) $\lim _{n \rightarrow \infty} b_{n}=0, \sum_{n=0}^{\infty} b_{n}=\infty$,

(ii) for each $i \in N$, $\liminf _{n \rightarrow \infty} a_{n} c_{n, i}>0$, $\liminf _{n \rightarrow \infty} c_{n, i} \gamma_{n, i}>0$, $\liminf _{n \rightarrow \infty} \beta_{n, i}>0$, and $\limsup _{n \rightarrow \infty} \gamma_{n, i}<2 /\left(\|A\|^{2}+1\right)$,

then the sequence $\left\{x_{n}\right\}$ converges strongly to $P_{\Omega} u$.

\section{Conflict of Interests}

The authors declare that they have no conflict of interests.

\section{Acknowledgment}

This work was supported by the Scientific Research Fund of Sichuan Provincial Education Department of China (no. 08ZA008).

\section{References}

[1] B. Martinet, "Regularisation d'inequations variationnelles par approximations successives," Revue Française D'informatique et de Recherche Opérationnelle, vol. 4, pp. 154-158, 1970.

[2] R. T. Rockafellar, "Monotone operators and the proximal point algorithm," SIAM Journal on Control and Optimization, vol. 14, no. 5, pp. 877-898, 1976.

[3] H. Brezis and P. L. Lions, "Produits infinis de resolvantes," Israel Journal of Mathematics, vol. 29, no. 4, pp. 329-345, 1978.

[4] O. Güler, "On the convergence of the proximal point algorithm for convex minimization," SIAM Journal on Control and Optimization, vol. 29, no. 2, pp. 403-419, 1991.

[5] S. Kamimura and W. Takahashi, "Approximating solutions of maximal monotone operators in Hilbert spaces," Journal of Approximation Theory, vol. 106, no. 2, pp. 226-240, 2000.

[6] S. Kamimura and W. Takahashi, "Strong convergence of a proximal-type algorithm in a Banach space," SIAM Journal on Optimization, vol. 13, no. 3, pp. 938-945, 2002.

[7] K. Nakajo and W. Takahashi, "Strong convergence theorems for nonexpansive mappings and nonexpansive semigroups," Journal of Mathematical Analysis and Applications, vol. 279, no. 2, pp. 372-379, 2003.

[8] M. V. Solodov and B. F. Svaiter, "Forcing strong convergence of proximal point iterations in a Hilbert space," Mathematical Programming, vol. 87, no. 1, pp. 189-202, 2000.

[9] C. S. Chuang, "Strong convergence theorems for the split variational inclusion problem in Hilbert spaces," Fixed Point Theory and Applications, vol. 2013, article 350, 2013.

[10] A. Moudafi, "Split monotone variational inclusions," Journal of Optimization Theory and Applications, vol. 150, no. 2, pp. 275$283,2011$.

[11] S. S. Chang, "On Chidume's open questions and approximate solutions of multivalued strongly accretive mapping equations in Banach spaces," Journal of Mathematical Analysis and Applications, vol. 216, no. 1, pp. 94-111, 1997.

[12] S. S. Chang, J. K. Kim, and X. R. Wang, "Modified block iterative algorithm for solving convex feasibility problems in Banach spaces," Journal of Inequalities and Applications, vol. 2010, Article ID 869684, 14 pages, 2010.

[13] F. E. Browder, "Fixed-point theorems for noncompact mappings in Hilbert space," Proceedings of the National Academy of Sciences of the United States of America, vol. 53, pp. 1272-1276, 1965.

[14] W. Takahashi, Nonlinear Functional Analysis-Fixed Point Theory and Its Applications, Yokohama Publishers, Yokohama, Japan, 2000 .

[15] Z. He and W. S. Du, "Nonlinear algorithms approach to split common solution problems," Fixed Point Theory and Applications, vol. 2012, article 130, 2012. 
[16] C. S. Chuang, L. J. Lin, and W. Takahashi, "Halpern's type iterations with perturbations in Hilbert spaces: equilibrium solutions and fixed points," Journal of Global Optimization, vol. 56, no. 4, pp. 1591-1601, 2013.

[17] M. Eslamian and A. Latif, "General split feasibility problems in Hilbert spaces," Abstract and Applied Analysis, vol. 2013, Article ID 805104, 6 pages, 2013.

[18] P. E. Mainge, "Strong convergence of projected subgradient methods for nonsmooth and nonstrictly convex minimization," Set-Valued Analysis, vol. 16, no. 7-8, pp. 899-912, 2008.

[19] K. Aoyama, Y. Kimura, W. Takahashi, and M. Toyod, "Approximation of common fixed points of a countable family of nonexpansive mappings in a Banach space," Nonlinear Analysis: Theory, Methods \& Applications, vol. 67, no. 8, pp. 2350-2360, 2007. 


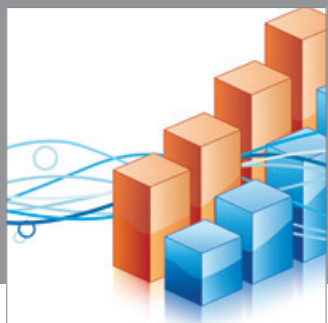

Advances in

Operations Research

mansans

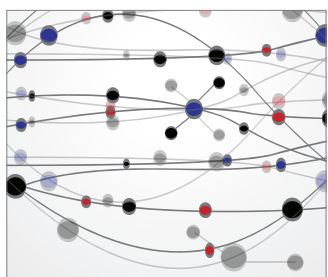

The Scientific World Journal
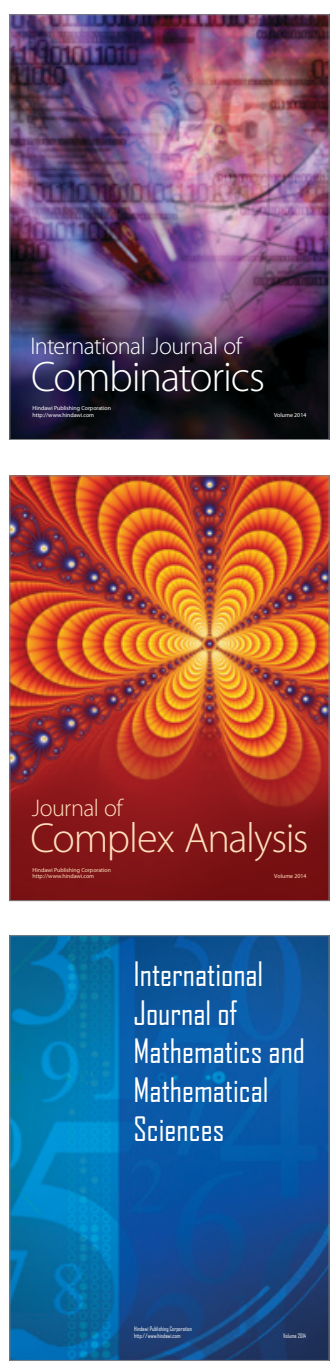
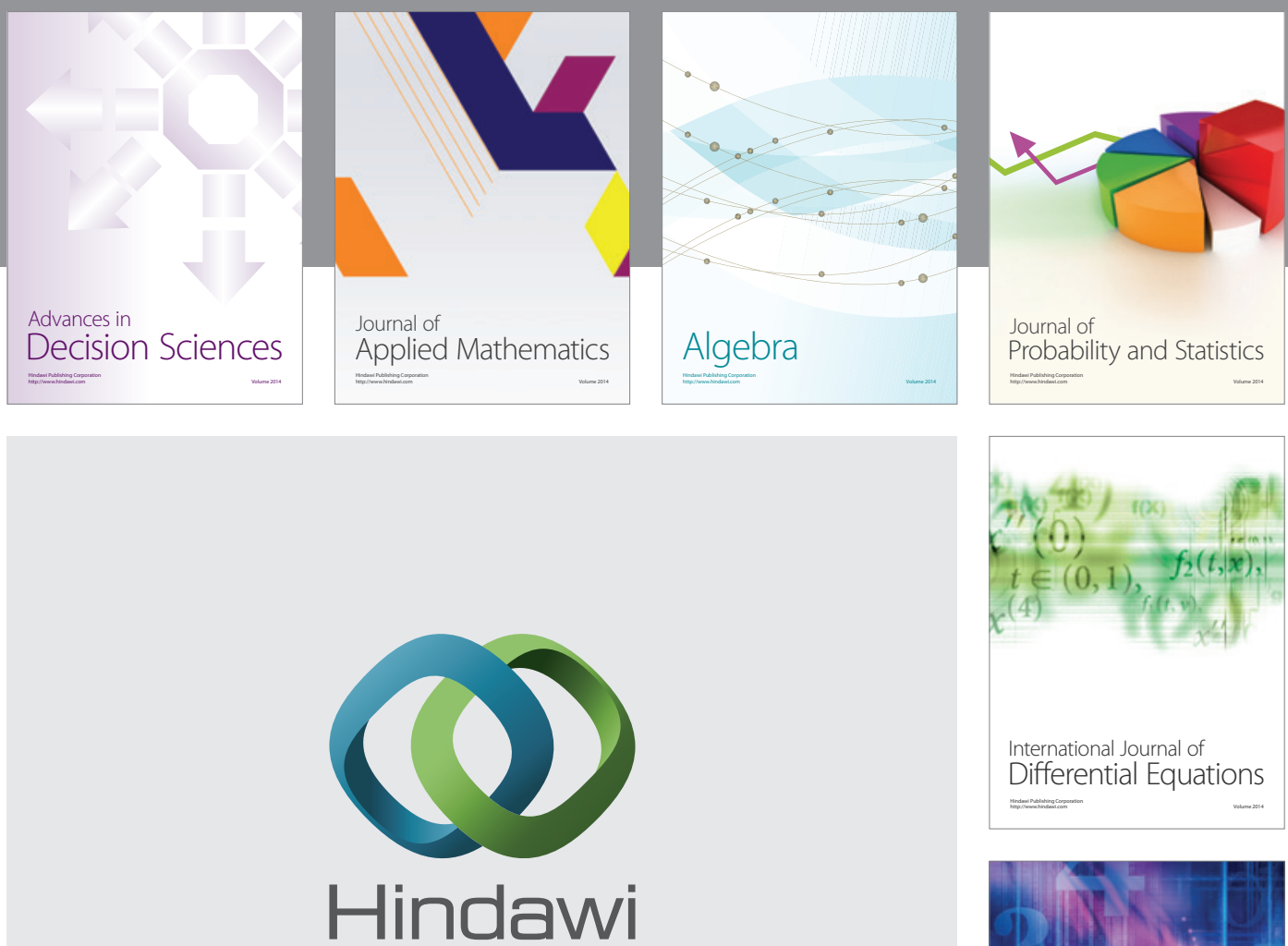

Submit your manuscripts at http://www.hindawi.com
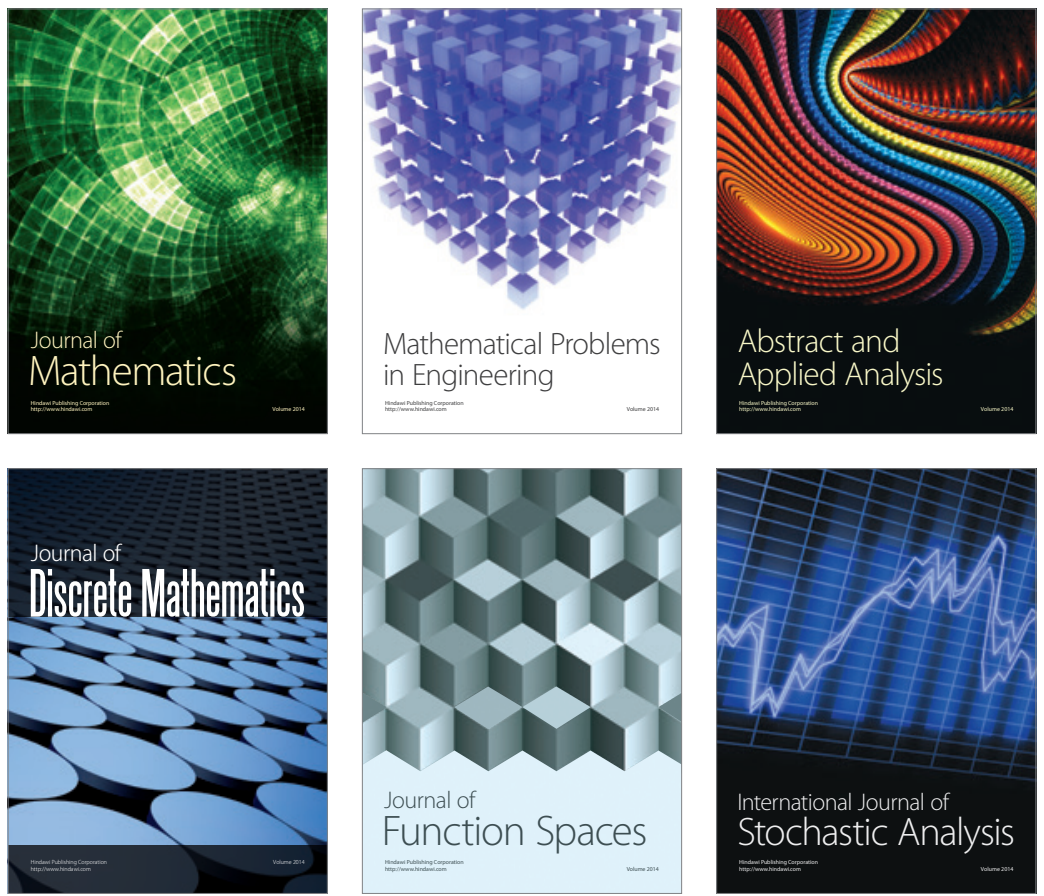

Journal of

Function Spaces

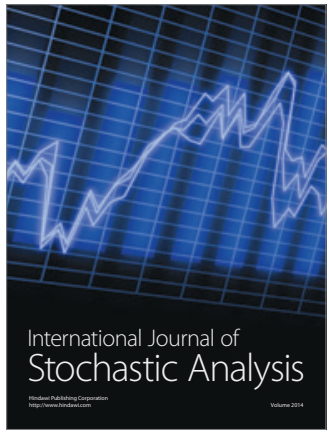

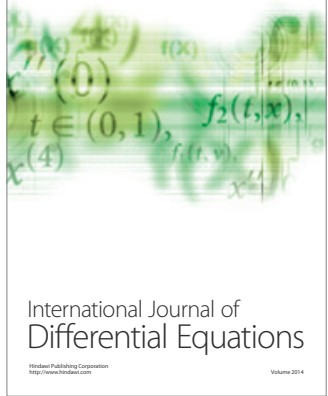
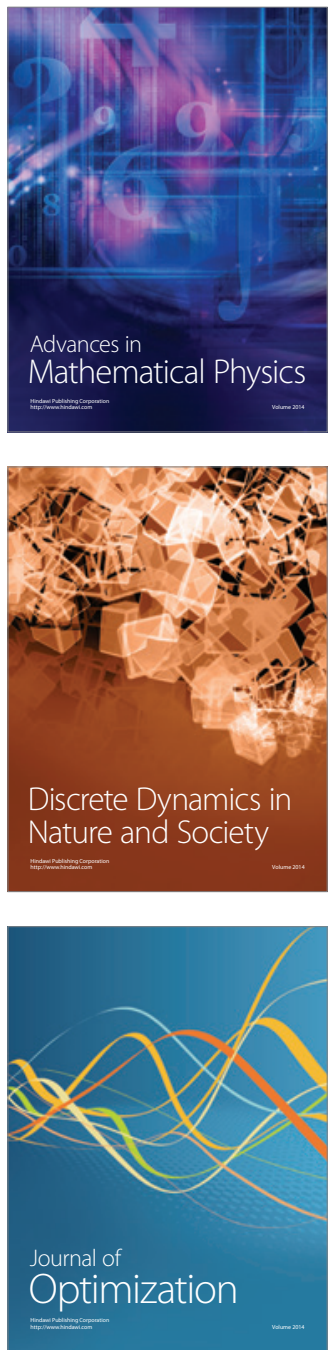